\title{
Vínculos e relações familiares de idosos institucionalizados
}

\author{
Juliana Rohde*, Silvia Virgínia Coutinho Areosa**
}

\section{Resumo}

Este estudo trata de famílias que decidiram institucionalizar seus idosos em Instituições de Longa Permanência para Idosos (ILPI's). Buscou-se conhecer sobre as motivações para terem tomado esta decisão, sobre os sentimentos gerados por isto e, se há manutenção do vínculo com o familiar idoso, como este é feito. Trata-se de um estudo de caso, de caráter qualitativo, do qual participaram 10 (dez) familiares de idosos instituciocalizados em uma ILPI particular no interior do Rio Grande do Sul. Os dados foram coletados por meio da realização de entrevistas semiestruturadas, e sua análise norteada pela análise de conteúdo de Bardin (2004). As categorias de análise das falas dos entrevistados são: motivos, que explicitam as razões que levaram as famílias a optarem pela institucionalização; sentimentos, que discorrem sobre como se sentiram estes familiares ao tomar a decisão de institucionalizar o idoso; e vínculos, que apontam quais são as estratégias utilizadas por estas famílias para realizar a manutenção do vínculo com o familiar institucionalizado. Esta pesquisa possibilitou reflexão acerca de como se dá o processo de institucionalização do idoso para a sua família, refletindo sobre os diversos aspectos que permeiam esta tomada de decisão.

Palavras-chave: Idosos. Família. Institucionalização. Vínculos afetivos. ILPIs.
Introdução

Muitos países vêm passando por uma transição demográfica, e com o Brasil não é diferente: o percentual de idosos na população é cada vez mais expressivo. Além disso, pode ser observado o aumento da longevidade, ou seja, as pessoas estão vivendo por mais tempo, o que representa uma vitória da humanidade frente aos obstáculos à sobrevivência. No entanto esta realidade traz à tona outras questões, como o suporte à população que envelhece e que, com frequência, demanda de cuidados e assistência (BARROS; GOMES JÚNIOR, 2013).

Esta transição populacional é causada pela queda dos níveis tanto de fecundidade quanto de mortalidade, pelas mudanças nos padrões de nupcialidade e nas configurações familiares. Soma-se a isto o aumento da escolaridade e da inserção das mulheres no mercado de trabalho, bem como a mudança dos seus papeis sociais. Essas modificações podem alterar os padrões de vínculo intergeracionais e já são perceptíveis transformações no cuidado com a população idosa (TARALLO, 2015).

* Psicóloga, residente multiprofissional no Hospital Santa Cruz.

*** Docente do Programa de Pós-Graduação em Desenvolvimento Regional e do Departamento de Psicologia da Universidade de Santa Cruz do Sul - UNISC.

$\rightarrow$ http://dx.doi.org/10.5335/rbceh.v17i1.8141 
Em 1982, havia cerca de 10 milhões de habitantes no país, e em 1990, essa população havia aumentado em torno de 15 vezes (ALCÂNTARA, 2009). Em 2010, no Brasil (IBGE, 2010), constatou-se que havia 20.590.599 idosos, o que é equivalente a cerca de $10,79 \%$ da população nacional. No mesmo ano, no Rio Grande do Sul, eram 1.459.597 idosos, correspondendo a $13,65 \%$ dos habitantes do estado, enquanto, em Santa Cruz do Sul, cidade onde foi realizado o presente estudo, a população idosa era de 15.559 pessoas, o que representava $13,14 \%$ dos moradores do município. Esses números representam crescimento desta população se compararmos aos dados do censo de 2000 (IBGE, 2000), uma vez que, naquele momento, o percentual de idosos no Brasil era de 8,57\%; no Rio Grande do Sul, de 10,45\%; e, em Santa Cruz do Sul, de $10,33 \%$.

O envelhecimento rápido e progressivo da população traz algumas preocupações, principalmente com a saúde e cuidados com os longevos. O processo de envelhecimento, mesmo quando ocorre de forma saudável, frequentemente acarreta em perdas funcionais, provocando comprometimentos na autonomia e na independência do idoso, gerando uma demanda de cuidados e atenção (DUTRA et.al., 2016).

Tradicional e historicamente, o cuidado com a pessoa idosa é atribuído à família, recaindo sobre ela a reponsabilidade de prover inúmeras necessidades, sejam físicas, psíquicas, sociais ou materiais, em especial se o idoso tem autonomia e independência comprometidas.
Este amparo por parte da família, além de ser garantido pelo Estatuto do Idoso, é um dever moral inscrito culturalmente (BRASIL, 2003; ESPITIA; MARTINS, 2006).

Antes do crescimento tão expressivo desta parcela da população, as famílias eram mais extensas e tinham poucos idosos, possibilitando que o cuidado fosse realizado no ambiente doméstico. É possível que o número de idosos precisando de cuidados aumente e a disponibilidade de cuidadores familiares diminua, de modo que outras formas de cuidado, como as Instituições de Longa Permanência para Idosos (ILPI's) se façam cada vez mais necessários (IPEA, 2008).

De acordo com o Estatuto do Idoso:

É obrigação da família, da comunidade, da sociedade e do Poder Público assegurar ao idoso, com absoluta prioridade, a efetivação do direito à vida, à saúde, à alimentação, à educação, à cultura, ao esporte, ao lazer, ao trabalho, à cidadania, à liberdade, à dignidade, ao respeito e à convivência familiar e comunitária (BRASIL, 2003, não paginado).

Porém, é socialmente esperado que a família dê conta desta necessidade, independentemente de ter ou não o apoio da sociedade e do Estado. No entanto, nem sempre isso acontece. Por muitas razões, as famílias podem não conseguir ou não desejar realizar esse cuidado com o seu idoso, decidindo delegar esta função às ILPI's (ALCÂNTARA, 2009; BULLA; MEDIONDO, 2010).

As ILPIs são a modalidade mais antiga de atenção aos idosos, e surgiram a fim de abrigar às pessoas desse grupo que fossem pobres ou não tivessem fa- 
mília (LEMOS; MEDEIROS, 2006). No Brasil, as ILPI's são majoritariamente de caráter residencial, objetivando oferecer domicílio coletivo para pessoas idosas, segundo a Resolução de Diretoria Colegiada no 283 da Agência Nacional de Vigilância Sanitária (BRASIL, 2005). Os cuidados com os idosos nesses espaços residenciais não envolvem procedimentos de alta complexidade, no entanto, há as dificuldades geradas por serem cuidados prolongados, repetitivos, com sobrecarga física e emocional para os cuidadores (YOSHITOME, 2010).

As ILPI's devem constituir-se enquanto espaços de atenção às necessidades da pessoa idosa, buscando não apenas oferecer moradia, mas também proporcionar qualidade de vida e bem-estar, independente das condições físicas, cognitivas, financeiras e familiares do idoso (KHOURY et al., 2011). Deve ser um lugar residencial que se adapte às necessidades dos seus moradores, permitindo que se possa viver com cidadania e dignidade.

Porém, de modo geral, a institucionalização do idoso apresenta-se como fator de risco para o rompimento de vínculos afetivos e sociais. A finitude dessas relações provoca medo, tensão, tristeza, angústia, desespero e insegurança. A partir daí, fica ainda mais clara a importância da manutenção do vínculo com a família, que exerce papel fundamental no equilíbrio emocional e afetivo do idoso (VIEIRA et al., 2016).

No entanto, há que se levar em conta que estas instituições surgiram para atender necessidades sociais, e conti- nuam desempenhando este papel, portanto ocupam um espaço na organização e no funcionamento da sociedade (VIEI$R A, 2003)$. Tendo em vista tais aspectos, esta pesquisa busca compreender como se dá o processo de institucionalização dos idosos para as famílias que optam por esta modalidade de cuidado.

$\mathrm{O}$ artigo está organizado com a seguinte sequência: apresentar-se-á, a seguir, a metodologia; posteriormente, serão apresentados e discutidos os dados, por meio de categorias de análise das falas dos entrevistados, que são: os motivos, que explicitam as razões que levaram as famílias a optar pela institucionalização; os sentimentos, que discorrem sobre como se sentiram estes familiares ao tomar a decisão de institucionalizar o idoso; e os vínculos, que apontam quais são as estratégias utilizadas por estas famílias para realizar a manutenção do vínculo com o familiar institucionalizado. Nas considerações finais, propõe-se reflexões sobre a temática do envelhecimento populacional e da institucionalização enquanto alternativa de suporte às demandas produzidas por este fenômeno.

\section{Método}

A pesquisa é do tipo estudo de caso qualitativo. As pesquisas qualitativas são interpretativas e não se espera do pesquisador imparcialidade e indiferença em relação ao seu objeto, que se envolve em uma experiência sustentada e intensiva com seus participantes (CRESWELL, 2010). Neste estudo, o 
caso é uma ILPI particular, matriz e filial, no interior do Rio Grande do Sul. Esta é uma metodologia que busca investigar e compreender uma realidade, de forma integral, descritiva e interpretativa. Permite que se investigue um contexto real, construindo conhecimento através da escrita científica, estruturada, interpretativa e crítica (COIMBRA; MARTINS, 2013).

Os participantes deste estudo responderam a uma entrevista semiestruturada, gravada e posteriormente transcrita. Foram entrevistados dez familiares de idosos institucionalizados, que aceitaram voluntariamente participar da pesquisa. Este estudo obteve aprovação no Comitê de Ética da Universidade de Santa Cruz do Sul (CAAE $\mathrm{n}^{\mathrm{o}}$ 70607617.8.0000.5343) e cumpriu com todos os requisitos éticos.

A análise dos dados, foi norteada pela metodologia de análise de conteúdo (BARDIN, 2004). Este tipo de metodologia não se limita ao conteúdo, e permite uma análise tanto dos significados quanto dos significantes. Este método possibilita inferir sobre variáveis psicológicas, sociológicas, culturais, relativas à situação de comunicação e contexto de produção da mensagem (AREOSA, 2015). As entrevistas buscavam investigar como aconteceu o processo de institucionalização do familiar, quais os motivos e os sentimentos gerados pela internação do idoso, bem como a manutenção de vínculos familiares na ILPI.

\section{Resultados e Discussão}

No município de Santa Cruz do Sul, atualmente, existem 28 ILPI's particulares, onde vivem 403 idosos, segundo informações obtidas junto ao Conselho Municipal do Idoso (CMI). De acordo com o órgão, estes números passaram por um crescimento significativo nos últimos quatro anos (foram abertas no município 11 novas ILPI's, e institucionalizadas mais 127 pessoas idosas), como se observa na tabela abaixo:

Tabela 1: Número de ILPI's e idosos institucionalizados em 2013 e 2017

\begin{tabular}{l|r|r}
\multicolumn{1}{c|}{ ANO } & \multicolumn{1}{c|}{2013} & \multicolumn{1}{c}{2017} \\
\hline Número de ILPI's & 17 & 28 \\
\hline Número de idosos & 276 & 403 \\
\hline
\end{tabular}

Fonte: Conselho Municipal do Idoso, 2017.

O início desta pesquisa deu-se pelo contato com o CMI, seguido da busca por alguma ILPI que aceitasse participar do estudo, intermediando o contato com os familiares dos idosos. Em datas autorizadas e combinadas com a coordenação da instituição que aceitou contribuir com o estudo, foram realizadas visitas a fim de abordar os familiares que estavam visitando os idosos, convidando-os a conceder uma entrevista. Um total de 10 pessoas foram entrevistadas, sendo que o perfil que mais teve participação foi o de adultos entre 44 e 57 anos, filhos(as) do(a) familiar institucionalizado(a). No entanto, também houve outros tipos de parentesco, como neta e irmã. O quadro a seguir permite visualizar com mais cla- 
reza aspectos do perfil dos participantes da pesquisa.

Quadro 1: Participantes da pesquisa

\begin{tabular}{|l|c|c|}
\hline Participante & Idade & $\begin{array}{c}\text { Parentesco com } \\
\text { o(a) idoso(a) } \\
\text { institucionalizado(a) }\end{array}$ \\
\hline Familiar 1 & 50 & Filho \\
Familiar 2 & 57 & Irmã \\
Familiar 3 & 56 & Filha \\
Familiar 4 & 44 & Filha \\
Familiar 5 & 20 & Neta \\
Familiar 6 & 66 & Filha \\
Familiar 7 & 52 & Filha \\
Familiar 8 & 54 & Filha \\
Familiar 9 & 55 & Filho \\
Familiar 10 & 53 & Filho \\
\hline
\end{tabular}

Fonte: Dados da pesquisa, 2017.

O conteúdo destas entrevistas possibilitou sua divisão em três categorias de análise, "Motivos", "Sentimentos" e "Vínculos", apresentadas e discutidas a seguir.

\section{Motivos}

Esta categoria trata das razões que motivaram os familiares a institucionalizarem os idosos em uma ILPI. Os motivos citados estão ligados à debilitação física e declínio cognitivo do idoso, falta de tempo para realização do cuidado, falta de preparo dos familiares para realizar alguns procedimentos e cuidados com os idosos, esgotamento do cuidador e o alto custo para manter cuidadores formais.

Bulla e Mediondo (2010) explicam que a institucionalização do idoso vai se apresentando como opção diante de algumas situações que se colocam na relação de cuidado. Algumas situações sugeridas pelas autoras estão em consonância com o que se evidenciou nas entrevistas: esgotamento físico e psicológico do cuidador após longo período de cuidados; falta de tempo, em razão de outras atividades da vida, como trabalho fora do lar e cuidado com crianças pequenas e intolerância às questões da velhice. Nas falas abaixo observa-se tais aspectos:

Ela perdeu todos os movimentos [...] E daí era difícil a gente lidar com ela [...]Ela não consegue caminhar, ela não consegue ir no banheiro, comer é com muita dificuldade (familiar 2 -irmã).

A gente tava com dificuldade de atender essas necessidades mais de saúde mesmo... ela tava engasgando e a gente não tava conseguindo fazer aspiração [...] E nós estávamos entrando em pânico, porque nós não tínhamos recursos pra prestar os socorros rapidamente como deveria [...] Eu tô cuidando da de cima e da de baixo (mãe e neta), e a gente fica estrangulado no meio e não pode parar de trabalhar (familiar 3-filha).

Eu até fiz algumas coisas, mas não tinha condição, de trabalho, e tempo... eu podia ficar com ela algumas horas do dia, umas 4 ou 5 horas por dia, o restante ela iria ficar sozinha, não tinha a menor condição (familiar 1 - filho).

A intensificação da condição de dependência dos idosos está diretamente associada à demanda e à busca das famílias pelas ILPI's (IPEA, 2008). Bulla e 
Mediondo (2010) reforçam este aspecto ao afirmarem que, a partir do momento em que o idoso passa a necessitar cuidados especiais e atendimentos contínuos e/ou intensivos, aumenta a probabilidade de que a família opte pela institucionalização desse idoso ou pelo auxílio de cuidadores profissionais. Em relação aos cuidadores formais, que seria uma alternativa à ILPI e ao cuidado realizado pelo familiar, um dos entrevistados diz:

Tentamos durante uns dois ou três meses que houvesse cuidadores com ela 24 horas por dia, só que era uma coisa que era muito difícil, porque, eventualmente, algum dos cuidadores dizia: "olha, não vou poder ir hoje". E aí? E aí alguém tinha que conseguir se desdobrar ou ficar mais, então acabava sendo uma situação muito instável, muito angustiante, e [...], além de tudo isso, é o custo, que acaba se tornando praticamente proibitivo ter pessoas 24 horas dentro de casa (familiar 10 - filho).

Silva, Santos e Rios (2017) falam da busca pelas ILPI's enquanto opção de moradia para os idosos porque, muitas vezes, a família não consegue arcar com os custos do idoso sem acarretar prejuízo próprio ou do restante da família. Nos achados do estudo, isso ocorre tanto nos aspectos financeiros (alimentação, medicação, assistência médica, cuidadores) quanto em custos à saúde e bem-estar dos familiares que realizam o cuidado. Esta última faceta pode ser claramente visualizada nestas três falas:

[...] A minha casa é pequena, e só tem um quarto e o quarto dos meus pais. Então, geralmente, eu acabava dormindo na sala e isso ficava bem desconfortável também, e isso acabava estressando meu pai, e meu pai brigava com a minha mãe e deu bastante problema lá em casa (familiar 5 - neta).

Porque minha irmã, eu tava vendo que ela tava ficando doente, ela não dormia.[...] Nós estávamos todos adoecendo, e avó junto, daí eu tive que convencer minha irmã que não dava mais (familiar 3 - filha).

A melhor coisa que uma pessoa que gosta do seu familiar pode fazer é colocar em clínicas especializadas. [...] Porque em casa tu acaba te cansando, te irritando com a pessoa, [...] eu tenho amigas que tão em casa cuidando dos parentes, da mãe, ou seja lá quem for, e já tão irritadas, já tão envelhecidas, já estão chatas, elas não têm mais vida, entendeu? Então elas estão abdicando... que abdicação é essa, ridícula? (familiar 6 - filha).

Os estudos sobre o cuidador afirmam que é imenso o investimento físico, emocional e socioeconômico do cuidador de um familiar dependente (CALDAS, 2003).Carter e McGoldrick (1995) explicam que os principais motivos são o fato de que a maioria das cuidadoras ainda são mulheres, só que agora inseridas no mercado de trabalho; de que os núcleos familiares estão cada vez menores, resultando em menor rede de suporte e menor possibilidade de divisão da responsabilidade de cuidar; e muitos familiares não se comprometem a contribuir com o cuidado..

A maioria dos entrevistados relatou vontade de permanecer cuidando do seu familiar idoso em casa, como forma de 
retribuir o cuidado recebido ao longo da vida, pelos vínculos e afeto, e por sentimento de dever moral. A institucionalização, para os entrevistados, apresenta-se como uma opção no momento em que se chega a um limite físico e emocional. (GIEHL et al., 2015, p.83).

Apesar de aparecerem sentimentos positivos na pesquisa das autoras acima, como gratificação e reciprocidade, há uma gama de sentimentos menos positivos, que conduzem ao esgotamento. Somente quando isso aconteceu, para os familiares entrevistados nesta pesquisa, é que houve a busca por uma instituição para realizar tais cuidados. Ao tomar a decisão institucionalizar e colocá-la em prática, surgiram sentimentos, que serão abordados na próxima categoria, "sentimentos".

\section{Sentimentos}

A decisão de institucionalizar é muito difícil. De acordo com Alcântara (2009), é comum que cause sentimento de culpa, impotência, remorso, e medo de enfrentar a opinião da sociedade, tendo em vista que não raro é entendida como abandono. Isso é reforçado ainda mais pelo fato de que, no contexto do Brasil, as instituições asilares são tratadas como tabu, espaço para os abandonados, um local para o qual não se deseja ir (KHOURY et al., 2011).

Nesta categoria, são abordados os sentimentos gerados pela decisão e ação de institucionalizar o idoso para os seus familiares. De acordo com os relatos, houve angústia, falta do convívio, sen- timentos como frustração e culpa por não poder ou não conseguir realizar o cuidado, e dificuldades de aceitar a debilitação do familiar idoso. No entanto, também houve tranquilidade e alívio por considerar que seu familiar está sendo cuidado por profissionais qualificados.

Diante da crença de que o melhor lugar para o idoso é no seio de sua família, a necessidade de recorrer a serviços geriátricos pode tornar-se alvo de muitos conflitos e angústias para os familiares. [...] São sentimentos de ambíguos, que se misturam com a história de vida de cada um, com uma inversão total de papéis que precisam ser refeitos (VIEIRA, 2003, p.61).

As falas relatadas a seguir mostram a ambivalência de sentimentos enfrentados pelos familiares.

É difícil. Porque a gente pensa em tudo isso. Ah, será que eu tô abandonando, será que eu tô fazendo certo.[...] A tua consciência diz "não, ela precisa disso, tu também precisa". A tua emoção diz "tu tá abandonando a tua mãe, tu não aguentou mais, é a tua mãe, ela cuidou de ti”. (familiar 4- filha).

Ah, a gente achou falta dela né assim, porque a gente se via todo dia né, todo dia, tanto é que semana que eu não venho aqui me dá um negócio ruim, sabe, por dentro, toda semana eu tenho que vir... (familiar 2 - irmã).

Um pouco de culpa, com certeza, culpa, impotência, hã... (familiar 3 - filha).

Eu até me senti bem inútil né, porque eu, como filha mulher, deveria estar cuidando né, me senti culpada e... eu achava que eu tinha que cuidar né (familiar 8 - filha).

Além dos sentimentos envolvidos na decisão de institucionalizar, evidenciou-se a preocupação dos familiares 
em relação à escolha da nova moradia do idoso. Grande parte deles relatou visitas em várias instituições antes de fazer a escolha, sempre buscando o local que, além de contemplar o orçamento da família, melhor se adequasse às necessidades do idoso e àquilo que era considerado indispensável enquanto condições estruturais, de assistência e cuidado. Os familiares faziam questão de reforçar este aspecto em vários momentos, talvez utilizando como recurso para tentar aliviar o sentimento de culpa, presente em praticamente todos os discursos. O pensamento do senso comum refere que os familiares querem "se livrar do problema" ao optarem pela institucionalização do idoso, reforçando a culpabilização dos filhos.

O problema é o "diz que diz que" das pessoas: "ai, que tu fez com a tua mãe, tu não tem coração, não sei o que". [...]Eu não me preocupo, mas meu irmão e a minha irmã sofreram muito com isso, porque eles dão bola. [...] se preocupam muito com o que o outro fala, com o que o outro sente... o que é que me interessa o outro? [...] Meus irmãos sofreram mais, eles custaram a se adaptar (familiar 6 - filha).

Mesmo quando não referida direta e explicitamente, a culpa era perceptível nas falas, uma vez que, em grande parte das entrevistas, logo após seu início, os participantes buscavam justificar a institucionalização do seu familiar citando o maior número de razões possível para que se chegasse à decisão. É importante referir que, quando se explicava sobre a pesquisa, deixava-se claro que o objetivo não era produzir julgamentos, mas sim conhecer a respeito de como acontecia este processo para as famílias.

A necessidade de reforçar este aspecto constantemente vai ao encontro da percepção de que existe um entendimento moralista da sociedade em relação à institucionalização, o que também foi encontrado no estudo de Stevens, Walshe e Baldwin (1993), que reforçam que os sentimentos de culpa e fracasso são comuns entre os familiares de idosos institucionalizados. Creutzberg et al. (2007) explicam que a relação entre a família e o idoso com as ILPI's em geral é marcada pela culpa, por indecisões e inseguranças.

A institucionalização dos idosos é ainda tabu, pois muitas famílias, por vezes, adiam o processo de institucionalizar apenas para evitar represálias ou para não se gerarem rumores. Deste modo, este processo torna-se [...] uma problemática familiar e também social, pois criam tensões e sentimentos de culpa. [...] Este processo surge, no entanto, por [...] como a última alternativa (PINHEIRO, 2016, p. 15).

Aparentemente a questão do dever moral de realizar os cuidados com o idoso ainda é bastante evidente, de forma que, quando a família não tem condições, sejam elas físicas, financeiras, emocionais, ou de estrutura da casa para prover os cuidados, e recorre a uma instituição, ainda assim sofre, pois pensa que será considerada negligente, omissa ou "ruim" pela sociedade. Apesar destes sentimentos mais negativos e difíceis perante a institucionalização do familiar idoso, também se encontraram senti- 
mentos positivos gerados pela decisão de institucionalizar, conforme relatam uma neta e um filho:

Foi mais tranquilo até... por ver que ela ia estar sendo mais cuidada, por ver que ela não ia ficar tipo... dar todo aquele trabalho em casa sem ser uma coisa muito boa pra ela (Familiar 5 -neta).

Alívio. Porque era uma preocupação constante né... não sabia como as coisas estavam. [...] Então, muitas vezes, eu tive que sair daqui pra ir lá resolver uma coisa e voltar no dia seguinte, ou voltar na mesma noite. Então é uma situação que ficava... realmente inviável, insustentável manter isso (Familiar 10 - filho).

Estas falas demonstram o alívio em relação à preocupação que antes se fazia presente em todos os momentos, e a tranquilidade por não precisar mais realizar os cuidados no ambiente doméstico. Estes discursos vão ao encontro daquilo que se sabe sobre a realização de cuidados com o idoso em casa: há custos emocionais, físicos e psíquicos para o cuidador, de forma que, quando estes cuidados já não são mais responsabilidade de quem antes os prestavam, surge a sensação de liberdade, alívio e tranquilidade.

Nardi, Sawada e Santos (2013) explicam que o ato de cuidar é de grande potencial estressor, uma vez que tem caráter crônico e sem tempo definido de duração, assim como traz preocupações em relação à evolução da saúde do idoso e ao provimento de assistência constante. Areosa et al. (2014) afirmam que muitos idosos são submetidos a cuidados insuficientes ou inadequados, sofrendo, por vezes, com maus-tratos e abandonos, em muitas ocasiões em decorrência da falta de apoio aos cuidadores em nosso país. Realizar o cuidado com o idoso dependente, sem uma retaguarda, é fator de exposição a doenças, estados emocionais negativos e desorganização da vida como um todo.

A respeito disto Mioto (2000, p. 219) afirma que: "famílias não são apenas espaços de cuidados, mas espaços a serem cuidados". Ou seja, a família não tem apenas de dar conta de realizar o cuidado com seus membros que precisam de apoio. Ela deve sim assumir sua responsabilidade diante destas situações, no entanto também deve ser amparada e cuidada. Uma família adoecida, desgastada pela realização do cuidado sem receber apoio, não consegue realizá-lo de forma adequada e também adoece.

Não ter mais esta responsabilidade cotidianamente explica os sentimentos de alívio e tranquilidade mencionados. Conforme observado na pesquisa, por vezes, após o momento da decisão tomada sobre a institucionalização do familiar idoso, os vínculos que estavam fragilizados pelo desgaste emocional podem ser fortalecidos.

\section{Vínculos}

Esta categoria discorre sobre os vínculos entre família e idoso institucionalizado: se há manutenção e permanência dos vínculos, e quais os recursos utilizados para que isto aconteça. Todos os familiares afirmaram que buscam manter o vínculo utilizando-se de recursos variados, como visitas, retirada do idoso da ILPI para passeios, visita à 
família e participação de comemorações, e o uso das novas tecnologias, como os aplicativos Skype e WhatsApp.

Espitia e Martins (2006) falam que, ao envelhecer, os sentimentos em relação à família se intensificam, e o sujeito passa a precisar de mais atenção e afeto. Pensando nisso, afirmam que a presença da família é muito importante para fornecer o suporte necessário. A partir desta realidade, torna-se interessante pensar sobre como esta família, que é provedora não apenas de cuidados físicos e práticos, mas também de afeto, amor, carinho e todos os sentimentos envolvidos nas relações familiares, mantém 0 vínculo com este ente institucionalizado. Os relatos abaixo podem nos ajudar a refletir a respeito.

Vêm, eles vêm visitar também, não com essa frequência, mas eles vêm, (irmãos da idosa institucionalizada). [...]. Dependendo, datas eu também levo ela pra casa, lá nos irmãos dela, mais em datas, aniversário... pra ela participar do almoço, das comemorações (familiar 1-filho).

Geralmente, no final de semana, eu sempre tiro ela daqui pra passear, passear pela cidade, ela sempre gosta de ver os jardins, [...], então a gente sempre faz isso, leva ela lá em casa durante algumas horas, e aí depois, perto da hora da janta, ela volta pra cá. (familiar 10 - filho).

É, eu venho uma vez por semana, né. [...] Eu viajo 5 horas, pra ficar duas horas com ela aqui. É bem cansativo, mas eu vejo que vale a pena. $E$ teve duas semanas que [...] eu não vim. E quando eu cheguei aqui, ela chorava muito. Ela já me abraçava chorando. Eu vim semana passada e ela tava bem depressiva, assim, bem bembembem. Aí eu vim hoje de novo, no feriado, e eu noto que ela já me recebeu com um sorriso. Então, eu noto que se eu consigo manter uma frequência ela fica bem. Se eu já passo mais de uma semana sem ver ela, ela já não fica. Então... eu tô aqui! (familiar 4 - filha).

De modo geral, a institucionalização apresenta-se como fator de risco para o rompimento de vínculos afetivos e sociais. A manutenção do vínculo com a família exerce papel fundamental no equilíbrio emocional e afetivo do idoso (Vieira et al., 2016).

Em todas as entrevistas realizadas, os familiares relataram visitas frequentes, bem como a utilização de outros recursos para manter as relações estreitas. Sabe-se, no entanto, que há outras realidades que em muito diferem desta. Silva et al. (2017) encontraram em seu estudo o dado de que uma das causas da institucionalização de idosos é o abandono pela família, e que, muitas vezes, quando esta não é a causa da ida do idoso para a ILPI, constuma acontecer depois, uma vez que, em muitos casos, com o tempo, os familiares deixam de fazer contato.

Perlini, Leite e Furini (2007) sugerem que a visitação é fator central para manutenção do vínculo, prestação de cuidados e vivências de atenção, carinho e afeto. Os mesmos autores referem que, à medida que o tempo de asilamento de um idoso aumenta, diminuem as visitas, provocando a fragilização destes laços, por isso dizem ser de suma importância que a visitação aconteça e seja estimulada.

No entanto, no caso desta pesquisa, percebeu-se que os familiares entrevis- 
tados são presentes e realizam esforços no sentido de que a visitação aconteça de forma regular e, na impossibilidade disto, outras estratégias têm sido empregadas pelas famílias para que o vínculo permaneça, principalmente utilizando as novas tecnologias:

A mãe participa do grupo (da ILPI, no WhatsApp).A gente fica recebendo sempre foto e notícia. Sempre que a mãe recebe, ela mostra pra gente. E quando a minha dinda vem, que ela vem mais frequente que a gente, ela faz filmagem com a gente lá também. $E$ a gente consegue ver ela (familiar 5-neta).

Eu comecei a trazer fotos e mostro no celular as fotos. Isso ela gosta, ela mostra o celular que quer ver as últimas fotos que eu tirei com a família ou o que for. Isso ela gosta (familiar 6 - filha).

Eu consigo vir vê-la, no máximo, a cada 3 dias, caso aconteça alguma necessidade, alguma situação aguda, o pessoal chama, o familiar pode vir a qualquer momento [...]. E em relação à minha irmã, [...] hoje com Skype ficou muito bom, ficou muito fácil. A gente consegue ligar, aí a mana conversa com ela, ela vem pouco, então tenta manter essa aproximação. Então até ficou melhor agora, porque antes, às vezes, passava uma semana, duas semanas sem que a minha irmã conseguisse vê-la lá, isso morando na mesma cidade, e agora pelo menos uma vez ou duas por semana, através de Skype, se consegue ter esse contato (familiar 10 - filho).

A busca por novas formas de estar próximo demonstra que as famílias têm procurado contato com o idoso institucionalizado, mesmo que através de tecnologias. No entanto, há que se levar em conta que esta é uma realidade encontrada em um recorte muito específico, uma casa geriátrica particular, de forma que não re- flete o que acontece em muitos outros espaços e ocasiões, tendo em vista a heterogeneidade do processo de envelhecimento no Brasil, e suas intensas desigualdades econômicas e sociais (CASTRO; BARROS JÚNIOR, 2016; CORTELETTI; CASARA; HERÉDIA, 2010).

\section{Considerações finais}

Esta pesquisa buscou conhecer a realidade das famílias que decidem institucionalizar seus idosos, a partir das motivações para tal, dos sentimentos gerados a partir desta situação e sob a ótica da manutenção de vínculos com o familiar na ILPI: se há ou não manutenção, e como é feita. Constatou-se que há uma ampla gama de razões que levaram estas famílias a optar por esta alternativa de cuidado, mas, em sua grande maioria, estão ligadas à exaustão dos cuidadores familiares, devido à intensificação da dependência, ou de algum quadro de doença do idoso.

Entre os sentimentos gerados para a família a partir da institucionalização do idoso, destacam-se os sentimentos de impotência, e especialmente a culpa, que foram recorrentes em grande parte dos discursos dos familiares. Constatou-se que as mulheres se identificam fortemente com o papel de cuidadora, enquanto um cargo que por elas deveria ser ocupado, o que está em consonância com a literatura (ALCÂNTARA, 2009; NERI; SOMMERHALDER, 2012). Ao não conseguirem realizar este cuidado, seja por incapacidades físicas, de tempo, de condições emocionais, ou quaisquer 
outras, sentem-se deixando de cumprir um dever que lhes era cabido, ou mesmo uma função que era socialmente esperada que realizassem.

Quanto à manutenção dos vínculos, no caso estudado por esta pesquisa familiares de idosos institucionalizados em uma ILPI particular - a manutenção acontece, e as visitas são regulares. Também, há por parte dos familiares, a utilização de outras formas de manterem-se próximo aos idosos institucionalizados, como a retirada do idoso da ILPI para passeios e retornos ao lar, o contato através da internet (aplicativos) e contato com fotos de familiares.

A inovação desta pesquisa diz respeito ao fato de dar voz aos familiares dos idosos institucionalizados. Sabe-se que há realidades muito distintas da encontrada neste estudo; em que a institucionalização ainda é sinônimo do abandono por parte da família, e que os vínculos de fato são rompidos quando isto acontece.

A institucionalização, apesar de apresentar-se como fator de risco para rompimento dos laços afetivos, e uma série de sentimentos e estados emocionais negativos aos idosos, é uma alternativa de cuidado que aparentemente tem se apresentado cada vez mais como uma opção. No entanto, ainda é permeada por uma série de estigmas, que são justificados pelo histórico deste tipo de instituição, bem como pela realidade de muitas que existem e não oferecem condições dignas às pessoas que abrigam.

Porém, há que se pensar em alternativas para o cuidado desta população que está envelhecendo, como apoio às fa- mílias que têm esta responsabilidade. $\mathrm{O}$ Estatuto do Idoso (BRASIL, 2003) prevê que o cuidado e o provimento dos direitos básicos para uma vida digna ao idoso é obrigação da família, da comunidade, da sociedade e do Poder Público, e não apenas da família, como se percebe que tem acontecido em nosso país.

\section{Links and relationships: families that institutionalized their elderly}

\section{Abstract}

This study speak about families who decided to institutionalize their elderly in Long-Term Institutions for the Elderly (ILPI's). It was sought to know about the motivations to have made this decision, about the feelings generated by it and, if there is maintenance of the bond with the elderly relative, how this is happens. This is a case study of a qualitative nature, in which 10 (ten) family members of elderly individuals were enrolled in a private $\mathrm{LPI}$ in the interior of Rio Grande do Sul. Data were collected through semi-structured interviews, and analysis based on the content analysis of Bardin (2004). The categories of analysis of the interviewees' speeches are: motives, which explain the reasons that led families to opt for institutionalization; feelings, which discuss how these family members felt when they decided to institutionalize the elderly; and links, which point out the strategies used by these families to maintain the bond with the institutionalized family member. This research allowed reflection on how the process of institutionalization of the elderly for their family occurs, thinking about several aspects that permeate it.

Keywords: Elderly. Families. Institutionalization. Bond. Feelings. Long-term care fa- 
cilities for the elderly.

\section{Referências}

ALCÂNTARA, A. O. Velhos institucionalizados e família: entre abafos e desabafos. 2. ed. Campinas, SP: Editora Alínea, 2009.

AREOSA, S. V. C, et. al. Cuidar de si e do outro: estudo sobre os cuidadores de idosos. Psicologia, Saúde \& Doenças, n. 15, v. 2, p. 482-494, 2014. Disponível em: <http:// dx.doi.org/10.15309/14psd150212>.

AREOSA, S. V. C. Caminhos metodológicos. In: AREOSA, S. V. C. (Org.). Envelhecimento e universidade: um estudo do Fórum Gaúcho das IES do Rio Grande do Sul. São Leopoldo, RS: Casa Leiria, 2015, p. 21-29.

BARDIN, L. Análise de conteúdo. Lisboa: Edições 70, 2004.

BARROS, R. H.; GOMES JÚNIOR, E. P. Por uma história do velho ou do envelhecimento no Brasil. CES revista, v. 27, n. 1, p. 72-92, 2013. Disponível em: <www.cesjf.br/revistas/ cesrevista/edicoes/2013/Artigo\%2004.pdf>.

BRASIL. Lei $\mathrm{n}^{\circ} 10.741$, de $1^{\circ}$ de outubro de 2003. Dispõe sobre o Estatuto do Idoso e dá outras providências. Diário Oficial [da] República Federativa do Brasil. Brasília, 1 out. 2003. Disponível em: <http://www.planalto. gov.br/ccivil_03/leis/2003/L10.741.htm>.

BRASIL. Resolução da Diretoria Colegiada $\operatorname{RDC} n^{\circ} 283$ de 26/09/2005. Aprova o regulamento técnico que define normas de funcionamento para as Instituições de Longa Permanência para Idosos, de caráter residencial. Diário Oficial [da] República Federativa do Brasil. Brasília, 27 set. 2005. Disponível em: <http://www.portal.anvisa.gov.br>.

BULLA, L. C; MEDIONDO, M. Z. Velhice, dependência e vida cotidiana institucional. In: CORTELETTI, I. A; CASARA, M. B; HERÉDIA, V. B. M. (Orgs.). Idoso asilado: um estudo gerontológico. Caxias do Sul, RS: Educs; Porto Alegre, RS: Edipucrs, 2010, p. 87-110.

CALDAS, C. P. Envelhecimento com dependência: responsabilidades e demandas da família. Caderno de Saúde Pública. Rio de Janeiro, v. 19, n. 3, p. 733-781, 2003. Doi: 10.1590/S0102-311X2003000300009

CARTER, B.; MCGOLDRICK, M. As mudanças no ciclo de vida familiar: uma estrutura para terapia familiar. Porto Alegre, RS: Artes Médicas, 1995.

CASTRO, S. F. F.; BARROS JÚNIOR, F. O. Atenção à Saúde do Idoso: o pensar e o fazer Políticas Públicas. Revista Kairós Gerontologia, São Paulo, v. 19, n.especial 22, p. 271-294, 2016. Disponível em: https:<// revistas.pucsp.br/index.php/kairos/article/ view/33580/23135>.

CRESWELL, J. W. Projeto de pesquisa: métodos qualitativo, quantitativo e misto. Porto Alegre, RS: ARTMED, 2010.

COIMBRA, M. N. C. T.; MARTINS, A. M. O. O estudo de caso como abordagem metodológica no ensino superior. Nuances, São Paulo, v. 24 , n. 3 , p. $31-46$, 2013. Doi: 10.14572/ nuances.v24i3.2696

CORTELETTI, I. A; CASARA, M. B; HERÉDIA, V. B. M. Institucionalização do idoso: identidade e realidade. In: CORTELETTI, I. A; CASARA, M. B; HERÉDIA, V. B. M. (Orgs.). Idoso asilado: um estudo gerontológico. Caxias do Sul: Educs; Porto Alegre: Edipucrs, 2010, p. 13-62.

CREUTZBERG, M.; GONCALVES, L. H. T.; SOBOTTKA, E. A.; SANTOS, B. R. L. DOS. A comunicação entre a família e a Instituição de Longa Permanência para Idosos. Revista Brasileira de Geriatria e Gerontologia, Rio de Janeiro, v. 10, n. 2, p. 147-160, 2007. Doi: 10.1590/1809-9823.2007.10022

DUTRA, R. R.; VARGAS, S. C.; TORNQUIST, L.; TORNQUIST, D.; MARTINS, V. A.; KRUG, S. F.; CORBELLINI, V. A. Refletindo sobre o processo de institucionalização do 
idoso. Revista de Epidemiologia e Controle de Infecção, Santa Cruz do Sul, v. 6, s. n., p. 1-9, 2016. Doi: 10.17058/reci.v1i1.8040

ESPITIA, A. Z.; MARTINS, J. J. Relações afetivas entre idosos institucionalizados e família: encontros e desencontros. Arquivos catarinenses de medicina. Santa Catarina, v. 35, n. 1, p. 52-29, 2006. Disponível em: <http://www.acm.org.br/acm/revista/pdf/ artigos/355.pdf $>$.

GIEHL, V. M.; ROHDE, J.; AREOSA, S. V. C.; BULLA, L. C. Quando se fala em doença de alzheimer: o papel do familiar cuidador de idosos. Revista Jovens Pesquisadores, Santa Cruz do Sul, v. 5, n. 3, dez. 2015. ISSN 2237-048X. DOI: 10.17058/rjp.v5i3.5739

IBGE - Instituto Brasileiro de Geografia e Estatística. Sinopse do censo demográfico 2010.Disponível em: <http://www.ibge.gov. br/home/estatistica/populacao/censo2010/ sinopse/sinopse_tab_uf_zip.shtm>.

IBGE - Instituto Brasileiro de Geografia e Estatística. Censo 2000. Disponível em: $<$ http://www.ibge.gov.br/home/estatistica/ populacao/default_censo_2000.shtm>.

IPEA - Instituto de Pesquisa Econômica Aplicada. Características das instituições de longa permanência para idosos: região Sul. Brasília: Presidência da República, 2008.

KHOURY, H. T. T. et al. Bem-estar subjetivo de idosos em instituições de longa permanência. In: FALCÃO, D. V. S.; ARAÚJO, L. F. (Orgs.). Psicologia do envelhecimento: relações sociais, bem-estar subjetivo e atuação profissional em contextos diferenciados. Campinas, SP: Alínea, 2011, p. 103-118.

LEMOS, N.; MEDEIROS, S. L. Suporte social ao idoso dependente. In: FREITAS, E. V; et.al. (Orgs.). Tratado de geriatria e gerontologia. Rio de Janeiro, RJ: Guanabara Koogan, 2006, p. 1228-1233.

MIOTO, R. C. T. Cuidados sociais dirigidos as famílias e segmentos sociais vulneráveis. In: Capacitação em Serviço Social e Politica Social: $O$ trabalho do assistente social e as políticas sociais. Brasília, DF: UNB, Centro de Educação Aberta, Continuada a Distância, 2000, p. 217-224.

NARDI, E. F. R.; SAWADA, N. O.; SANTOS, J. L. F. Associação entre a incapacidade funcional do idoso e a sobrecarga do cuidador familiar. Revista Latino-Americana de Enfermagem, Ribeirão Preto, v. 21, n. 5, p. 1-8, 2013. Doi: 10.1590/S010411692013000500012

NERI, A. L.; SOMMERHALDER, C. As várias faces do cuidado e do bem-estar do cuidador. In: NERI, A. L. (org.). Cuidar de idosos na família: questões psicológicas e sociais. Campinas, SP: Alínea, 2012, p. 11-68.

PERLINI, N. M. O. G.; LEITE, M. T.; FURINI, A. C. Em busca de uma instituição para a pessoa idosa morar: motivos apontados por familiares. Revista de Escola de Enfermagem da USP, São Paulo, v. 41, n. 2, p. 229-236, 2007. Doi: 10.1590/S008062342007000200008 .

PINHEIRO, D. P. (2016). Promoção do desenvolvimento cognitivo em idosos com a doença de Alzheimer - as práticas e os contextos de Estruturas Residenciais para Idosos. (Dissertação de Mestrado). Instituto Politécnico Leiria. Leiria, Portugal, 2016.

SILVA, A. C. F.; SANTOS, M. F.; RIOS, T. I. O processo de institucionalização: o que muda na vida da pessoa idosa? REFACS, Uberaba, v. 5 , n. 1, p. 346-353, 2017. Doi: 10.18554/ refacs.v5i0.2268

SILVA N. M. N; AZEVEDO, A. K. S.; FARIAS, L. M. DA S.; LIMA, J. DE M. Characteristics of a long-stay institution for the elderly. Revista On Line de Pesquisa Cuidado é Fundamental, v. 9, n. 1, p. 159-166, 2017. Doi: 10.9789/2175-5361.2017.v9i1.159-166

VIEIRA, S. K. S. F.; ANJOS, M. N. C. DOS; SANTOS, F. A. N. DOS, DAMASCENO, C. K. C. S.; SOUSA, C. M. M. DE; OLIVEIRA, A. D. DA S. Avaliação da qualidade de vida de idosos institucionalizados. Revista Interdisciplinar, Teresina, v. 9, n. 4, p. 1-11, 2016. 
Disponível em: <http://revistainterdisciplinar.uninovafapi.edu.br/index.php/revinter/ article/view/1155>.

VIEIRA, E. B. Instituições geriátricas: avanço ou retrocesso? Rio de Janeiro, RJ: Revinter, 2003.

TARALLO, R. S. As relações intergeracionais e o cuidado do idoso. Revista Kairós Gerontologia, São Paulo, v. 18, n. especial 18, p. 39-55, 2015.Disponível em: <https:// revistas.pucsp.br/index.php/kairos/article/ view/26592>.

YOSHITOME, A. Y. Atenção ao idoso em instituições de longa permanência: o enfoque da enfermagem. In: DOMINGUES, M. A.; LEMOS, N. D. Gerontologia: os desafios nos diversos cenários da atenção. Barueri, SP: Manole, 2010, p. 471-476. 